Pediatr Radiol (1989) 20: 52-56

\title{
MRI of surgically created pulmonary artery narrowing in the dog
}

\author{
R.J.Hernandez, A.P. Rocchini, E. L. Bove, T.L.Chenevert and B. Gubin \\ Department of Radiology, University of Michigan Medical Center, Ann Arbor, Michigan, USA
}

\begin{abstract}
Narrowing of the pulmonary arteries was created surgically in twelve dogs. In six of the dogs the narrowing was central (main pulmonary artery), and in the remaining six the narrowing was located peripherally at the hilar level of the right pulmonary artery beyond the pericardial reflection. MRI and angiography were performed in all dogs. MRI clearly delineated the site of the pulmonary band and the caliber of the pulmonary artery at the site of the band in all dogs $(N=6)$. MRI was not able to visualize any of the stenosis of the right pulmonary arteries at the hila, beyond the pericardial reflection. In addition, optimal imaging planes to depict each segment of the central pulmonary arteries were determined. The capability to image in oblique planes is essential in evaluating the morphology of the central pulmonary arteries.
\end{abstract}

Narrowing of the pulmonary arteries can be managed by balloon angioplasty [1,2]. Noninvasive techniques such as ultrasound and computerized tomography (CT) are desirable to monitor the effectiveness of therapy. Although these modalities are highly accurate in visualizing the main and right pulmonary arteries visualization of the intrapericardial portion of the left pulmonary artery especially its origin, is difficult [3]. The hilar portion of the pulmonary arteries cannot be adequately imaged by CT or ultrasound (US).

Abbreviations used in Figs.1-3: AA=Ascending aorta; $\mathrm{DA}=$ Descending aorta; $\mathrm{MPA}=$ Main pulmonary artery; LPA $=$ Left pulmonary artery; RPA $=$ Right pulmonary artery; $\mathrm{T}=$ Trachea; $\mathrm{E}=$ Esophagus; $\mathrm{RB}=$ Right bronchus; $\mathrm{LB}=\mathrm{Left}$ bronchus
Previous reports [4-8] have described the promising role of MRI in the evaluation of the pulmonary arteries in children with congenital heart lesions. We undertook the present study to determine the role of MRI in detecting and evaluating localized narrowing of the pulmonary arteries centrally and at the hilar level beyond the pericardial reflection. In addition, we determined optimal imaging planes to depict each segment of the central pulmonary arteries.

\section{Methods}

Stenoses were surgically created, using 2-0 Vicryl suture material, in 12 dogs. Six dogs had bands placed across the main pulmonary artery at 3-7 days of age. The other six dogs (age 3-8 yrs.) had stenosis of the right pulmonary artery surgically created just beyond the pericardial reflection behind the superior vena cava. The time interval between the surgical procedure and the study was approximately one year for the banding of the main pulmonary artery and two to five months for the stenosis of the right pulmonary artery.

All dogs had MRI scans and angiograms performed within two months $(N=10)$ or six months $(N=2)$ of each other. Angiography was performed using a femoral approach. Hand injections of contrast were made in the main pulmonary artery near the pulmonary valve. Filming was done in the frontal and lateral projections. In addition, those dogs with RPA stenosis had selective injections of contrast made in the right pulmonary artery with proximal balloon occlusion. Filming was performed using single exposures timed to coincide with optimal contrast opacification of the pulmonary arteries. The MRI scans were performed using a $1.5 \mathrm{~T}$ superconductive magnet (GE signa) with a $14 \mathrm{~cm} \times 30 \mathrm{~cm}$ rectangular surface coil. Spin-echo sequences had an echo delay time of $20 \mathrm{msec}$. In addition, respiratory and cardiac gating were performed: Cardiac gating accomplished by a trigger data acquisition process, caused the R-wave to initiate a view; the R-R time determined the pulse repeated time. The trigger delay was 

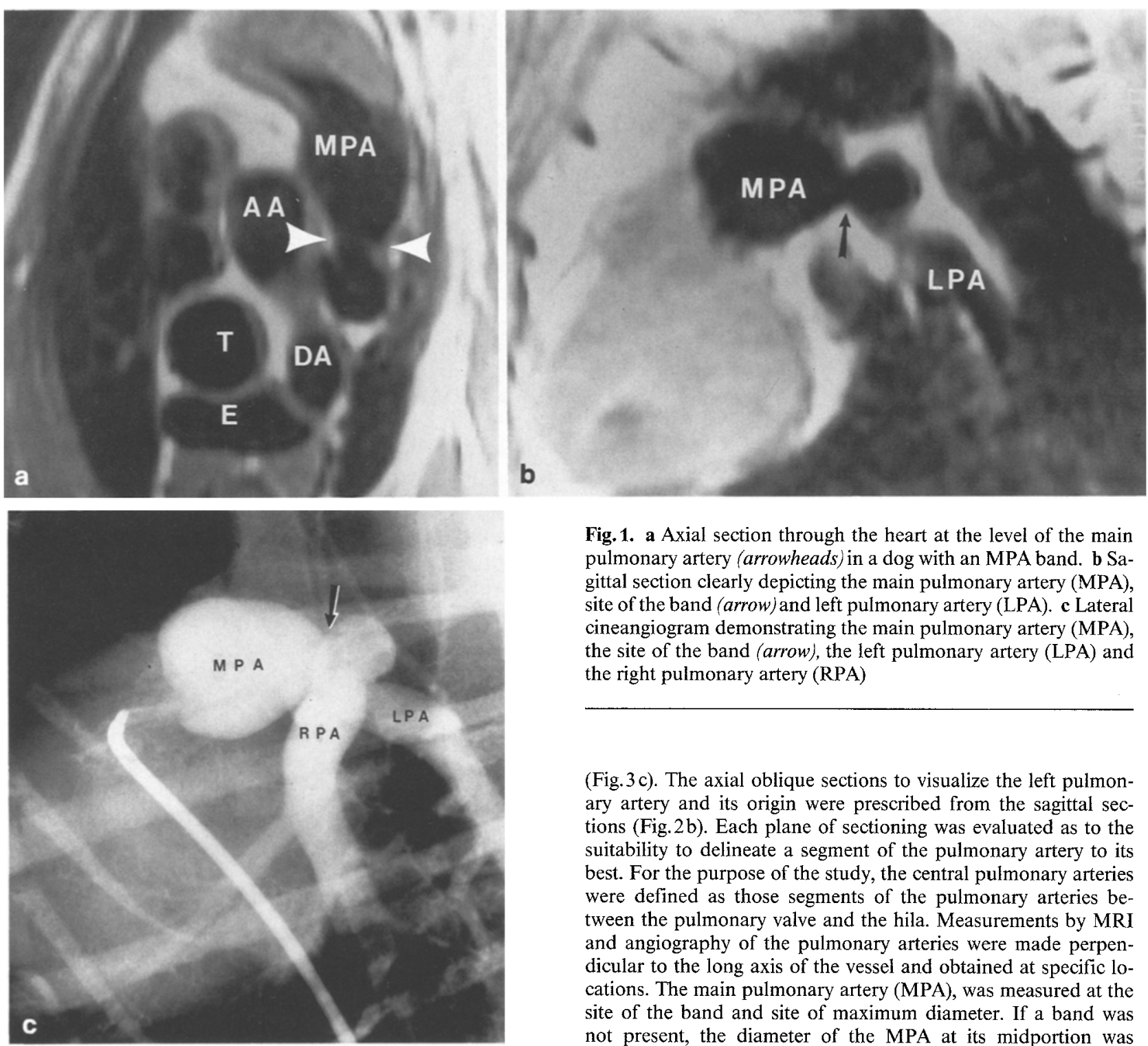

$100 \mathrm{msec}$, and the intersequence delay was minimal. Using four excitations per view, we obtained 5-6 slices $(5 \mathrm{~mm}$ thick with a $1 \mathrm{~mm}$ gap) by employing a multislice technique. Images were reconstructed using $256 \times 128$ matrix.

Sections were obtained in the axial, sagittal, and oblique planes. The oblique planes were determined from the axial and sagittal images. The coronal oblique sections to visualize the right pulmonary artery were prescribed from the axial images

Table 1. Correlation coefficients between angiography and MRI by each observer

\begin{tabular}{lll}
\hline & Observer 1 & Observer 2 \\
& $r$ & $r$ \\
\hline MPA & $0.77^{*}$ & $0.60^{* *}$ \\
RPA & $0.76^{*}$ & $0.57^{* * *}$ \\
LPA & $0.68^{* *}$ & $0.61^{* * *}$ \\
MPA Stenosis & 0.61 & $0.90^{* * *}$ \\
\hline
\end{tabular}

* $P<0.01$; ** $P<0.025$; *** $P<0.05$

Fig. 1. a Axial section through the heart at the level of the main pulmonary artery (arrowheads) in a dog with an MPA band. b Sagittal section clearly depicting the main pulmonary artery (MPA), site of the band (arrow) and left pulmonary artery (LPA). c Lateral cineangiogram demonstrating the main pulmonary artery (MPA), the site of the band (arrow), the left pulmonary artery (LPA) and the right pulmonary artery (RPA)

(Fig. 3 c). The axial oblique sections to visualize the left pulmonary artery and its origin were prescribed from the sagittal sections (Fig. 2b). Each plane of sectioning was evaluated as to the suitability to delineate a segment of the pulmonary artery to its best. For the purpose of the study, the central pulmonary arteries were defined as those segments of the pulmonary arteries between the pulmonary valve and the hila. Measurements by MRI and angiography of the pulmonary arteries were made perpendicular to the long axis of the vessel and obtained at specific locations. The main pulmonary artery (MPA), was measured at the site of the band and site of maximum diameter. If a band was not present, the diameter of the MPA at its midportion was determined. The right pulmonary artery (RPA) was measured behind the ascending aorta. The left pulmonary artery (LPA) was measured shortly after takeoff from the main pulmonary artery. MRI measurements were made on the axial sections using electronic calipers. The sagittal MRI sections were used to measure the MPA in those dogs with banding of the MPA, since these sections corresponded more closely to the angiograms. The angiography measurements were corrected for magnification using the known catheter diameter. Two sets of measurements of the cental pulmonary arteries by angiography and MRI were made independently by two observers without knowledge of the other observer's measurements. Measurements were correlated using nonparametric statistical methods.

\section{Results}

MRI enabled us to visualize all segments of the central pulmonary arteries. Axial sections best depicted the main and right pulmonary artery (Fig.1), sagittal 

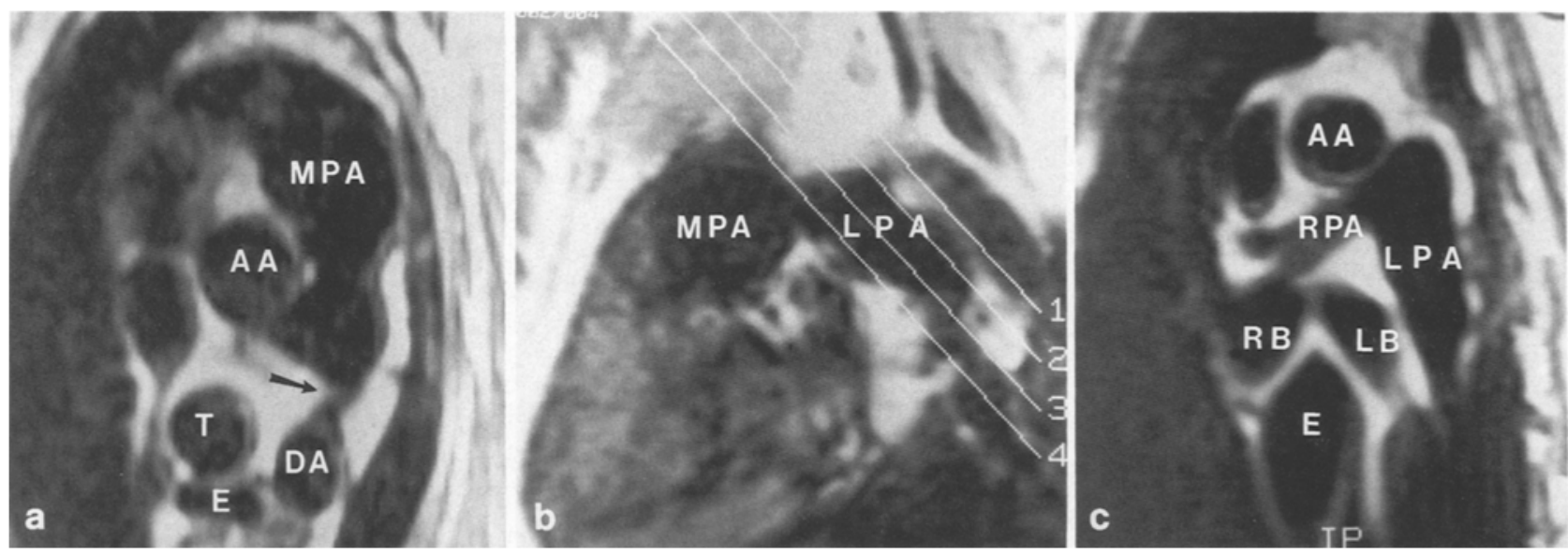

Fig. 2. a Axial section of a dog with a band in the main pulmonary artery. The origin of the left pulmonary artery (LPA) (arrow) could not be clearly visualized. $\mathbf{b}$ Imaging plane selected from the sagittal sections to obtain axial oblique sections. The plane of sectioning coincided with the course of the left pulmonary artery. $\mathrm{c} \mathrm{Ob-}$ lique coronal section clearly depicting the course of the left pulmonary artery (LPA)

sections best depicted the main and left pulmonary arteries (Fig. 2). The axial oblique section optimally depicted the origin of the left pulmonary artery (Fig.2). The coronal oblique section best depicted the right pulmonary artery (Fig. 3).

MRI clearly delineated the site of the pulmonary band and the caliber of the main pulmonary artery at the site of the band in all dogs $(N=6)$. MRI provided excellent visualization of the caliber of the MPA at the site of the band. In angiography, due to the overlapping of the post-stenotic segments, the actual site of narrowing was sometimes difficult to visualize clearly. MRI was not able to visualize any of the pulmonary stenosis in the right pulmonary arteries beyond the pericardial reflection.

The correlation coefficient between the caliber determinations of the central pulmonary arteries by MRI and angiography are listed in Table 1 . The caliber determinations were also analyzed for intraobserver and interobserver agreement. These correlation coefficients are listed on Tables 2 and 3.

\section{Discussion}

MRI is able to visualize the central pulmonary arteries with a high degree of accuracy. Although MRI accurately recognizes localized narrowing of the central pulmonary arteries, MRI does not visualize stenosis of the pulmonary arteries at the hilar level be- yond the pericardial reflection. The ability to image in the oblique planes is essential to evaluate the pulmonary arteries.

Branch pulmonary arterial hypoplasia or 10calized narrowing can occur as isolated lesions [9], as part of tetralogy of Fallot, or as pulmonary atresia with a ventricular septal defect. In addition to congenital etiologies, surgical procedures such as previous shunts or placement of bands can cause localized narrowing of the pulmonary arteries. Banding of the main pulmonary artery is frequently used to treat infants with congenital heart malformations which results in excessive pulmonary blood flow. Relief of pulmonary artery obstruction

Table 2. Intraobserver correlation coefficients for angiography and MRI

\begin{tabular}{lll}
\hline & $\begin{array}{l}\text { Angiography } \\
r\end{array}$ & $\begin{array}{l}\text { MRI } \\
r\end{array}$ \\
\hline Observer 1 & & \\
MPA & $0.99^{*}$ & $0.84^{*}$ \\
RPA & $0.94^{*}$ & $0.95^{*}$ \\
LPA & $0.95^{*}$ & $0.93^{*}$ \\
MPA Stenosis & $0.97^{* *}$ & $1.00^{* *}$ \\
Observer 2 & & \\
MPA & $0.99^{*}$ & $0.87^{*}$ \\
RPA & $0.96^{*}$ & $0.96^{*}$ \\
LPA & $0.99^{*}$ & $0.91^{*}$ \\
MPA Stenosis & $0.92^{* *}$ & $0.90^{* *}$ \\
\hline
\end{tabular}

* $P<0.005 ;{ }^{* *} P<0.05$

Table 3. Interobserver correlation coefficients for angiography and MRI

\begin{tabular}{lll}
\hline & $\begin{array}{l}\text { Angiography } \\
r\end{array}$ & $\begin{array}{l}\text { MRI } \\
r\end{array}$ \\
\hline MPA & $0.99^{*}$ & $0.71^{* * *}$ \\
RPA & $0.89^{*}$ & $0.95^{*}$ \\
LPA & $0.97^{*}$ & $0.83^{*}$ \\
MPA Stenosis & $0.98^{* *}$ & $0.90^{* *}$ \\
\hline
\end{tabular}

* $P<0.005 ; * * P<0.05 ; * * * P<0.01$ 

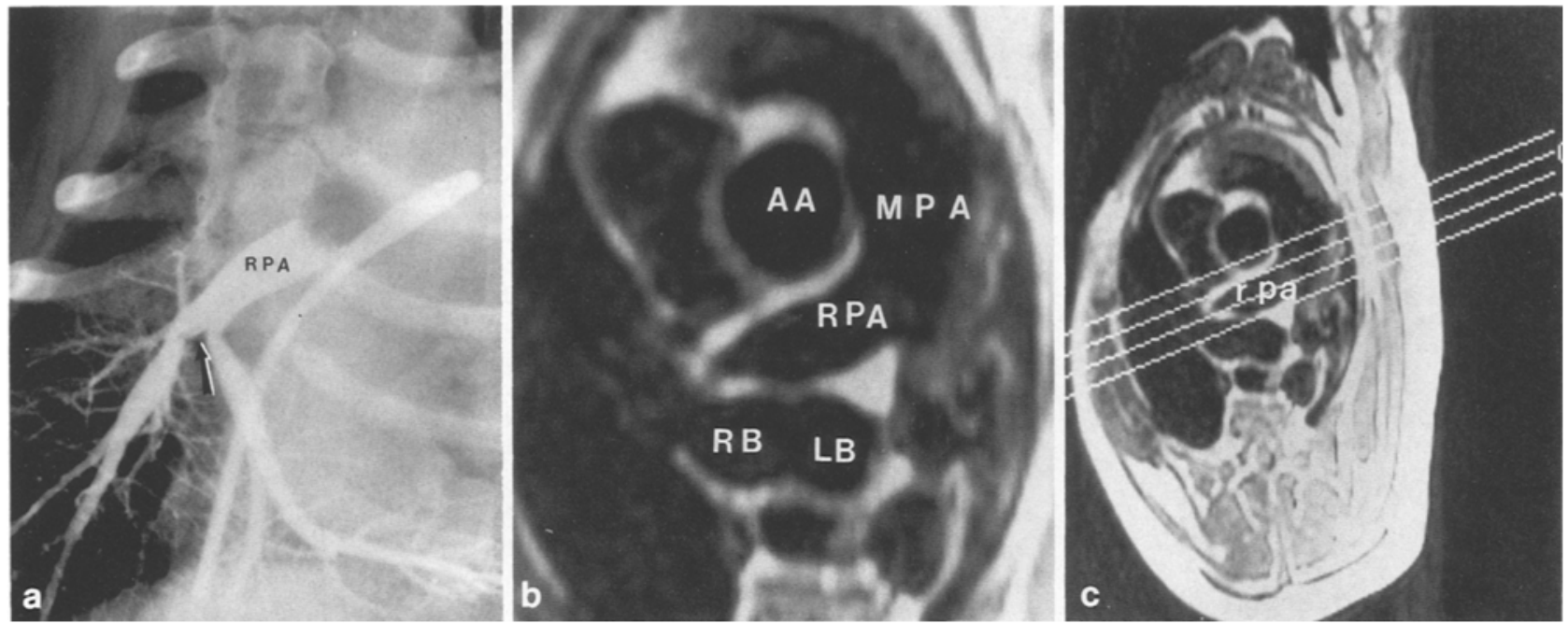

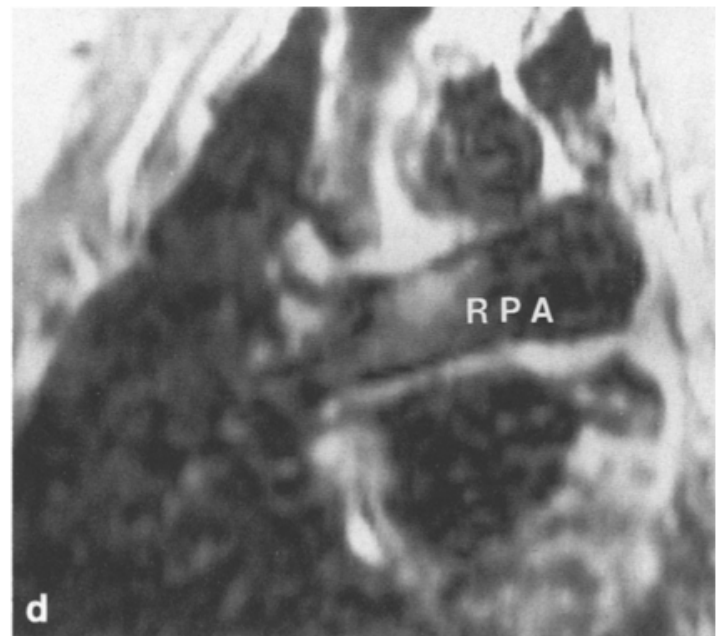

is often required. Although surgical relief has been the usual method employed to relieve the obstruction, recently the use of percutaneous balloon angioplasty has replaced surgery in some cases $[1,2$, $10]$.

Noninvasive techniques such as CT, US and MRI are useful in evaluating the effects of therapy. Although highly accurate in visualizing the right and main pulmonary arteries, CT and US fail in visualizing the origin and intrapericardial portion of the left pulmonary artery [3]. From our study, it is clear MRI can recognize stenosis of the central pulmonary arteries, and can depict clearly the origin and intrapericardial portion of the LPA. Nevertheless, MRI cannot recognize stenosis of the pulmonary arteries at the hila. This inability to recognize stenosis at the hilar level is felt to be secondary to two factors. The first is the lack of signal of the adjacent lung which masks the pulmonary vessels. Although the use of cardiac gated gradient recalled sequences such as cine would make inflowing blood appear bright and offer positive contrast,
Fig.3. a Angiogram of the right pulmonary artery (RPA) with proximal balloon occlusion. Localized narrowing of the right pulmonary artery at the pericardial reflection (arrow). b Axial section clearly visualizing the main pulmonary artery (MPA) and right pulmonary artery (RPA). There is a suggestion of narrowing of the RPA with tapering near the hilum. c Plane of sectioning prescribed on the axial images along the course of the right pulmonary artery (RPA). This plane of sectioning resulted in oblique coronal images. d Coronal oblique section clearly demonstrating a normal right pulmonary artery with no evidence of stenosis. The narrowing present on the axial image was due to an artifact from the plane of sectioning and the course of the vessel. The narrowing of the RPA at the hilar level could not be reconized

there is a tradeoff for the use of these sequences. The presence of susceptibility gradients at the tissue air interface can produce false signal voids. The second factor is that pulmonary arteries at this level often change direction preventing examination in a single plane.

Since pulmonary arteries often have a course which is not easily depicted by standard ortogonal (sagittal, axial and coronal) planes of imaging, the need to image in the oblique planes is essential to visualize optimally the pulmonary arteries. Sections which are along the plane of the pulmonary artery should be utilized. These planes will have to be customized to each patient. The axial and sagittal planes best depict the main pulmonary artery. Sections obtained in the axial and the coronal oblique planes selected from the axial images provide the best views of the right pulmonary artery. The left pulmonary artery, however, is best visualized in the sagittal plane or the axial oblique determined from the sagittal sections.

Although angiography has limitations as a gold standard (i.e. overlapping of pre and poststenotic segments, difficulty in visualizing the origin of the RPA in a dog, etc.), nevertheless angiography pro- 
vides a more physiologic evaluation of the pulmonary arteries than postmortem examination.

MRI, with capability to image in oblique planes, can depict the morphology of the central pulmonary arteries with a high degree of accuracy. MRI cannot image the hilar portion of the pulmonary arteries beyond the pericardial reflection.

Acknowlegements. We would like to express our appreciation for the help of the following people: Diane M. Bondie, B.S., Susan DeRemer, L.V.T., Margaret Hashoian, R.T. and Catherine P. Morehead, M.S. Without their support this project could not have been carried out.

\section{References}

1. Rocchini AP, Kveselis D, Dick M, Crowley D, Snider AR, Rosenthal A (1984) Use of balloon angioplasty to treat peripheral pulmonary stenosis. Am J Cardiol 54: 1069

2. Lock JE, Castaneda-Zuniga WR, Fuhrman BP, Bass JL (1983) Balloon dilation angioplasty of hypoplastic and stenotic pulmonary arteries. Circulation 67:962

3. Hernandez RJ, Bank ER, Shaffer EM, Snider AR, Rosenthal A (1987) Comparative evaluation of the pulmonary arteries in patients with right ventricular outflow tract obstructive lesions. AJR 148: 1189

4. Fletcher BD, Jacobstein MD (1986) MRI of congenital abnormalities of the great arteries. AJR 146: 941
5. Formanek AG, Witcofski RL, D'Souza VJ, Link KM, Karstaedt N (1986) MRI imaging of the central pulmonary arterial tree in conotruncal malformation. AJR 147:1127

6. Jacobstein MD, Fletcher BD, Goldstein S, Riemenschneider TA (1985) Magnetic resonance imaging in patients with hypoplastic right heart syndrome. Am Heart J 110: 154

7. Kersting-Sommerhoff BA, Sechtem UP, Higgins CB (1988) Evaluation of pulmonary blood supply by nuclear magnetic resonance imaging in patients with pulmonary atresia. $\mathbf{J}$ Am Coll Cardiol 11: 166

8. Rees RSO, Somerville J, Underwood SR, et al. (1987) Magnetic resonance imaging of the pulmonary arteries and their systemic connections in pulmonary atresia: comparison with angiographic and surgical findings. Br Heart $\mathbf{J} 58: 621$

9. Orell SR, Kainell J, Wahlgren F (1960) Malformation and multiple stenosis of the pulmonary arteries with pulmonary hypertension. Acta Radiol [Diagn] (Stockh) 54: 449

10. Vince DJ, Culham JAG, Taylor GP (1987) Balloon-dilatable arterial banding prosthesis: experimental study. Radiology 164: 141

Received: 11 January 1989; accepted: 18 March 1989

R.J.Hernandez, M.D.

Section of Pediatric Radiology

C.S. Mott Children's Hospital

University of Michigan Medical Center

1500 E. Medical Center Drive

Ann Arbor, MI 48109-0252

USA

\section{Literature in pediatric radiology (continued from p. 32)}

Osteomalazie bei ausländischen Jugendlichen in der Bundesrepublik Deutschland (Vitamin-D-Mangelrachitis) Kuwertz-Bröking, E. et al. (Pädiatrische Nephrologie, Univ.-Kinderklinik, Domagkstr.3, D-4400 Münster, FRG) 38, 647 (1989)

Einseitige Pseudohypertrophie des M. triceps surae bei einem neugeborenen Mädchen. Hinz, P. et al. (Kinderchirurg. Abt. des Chirurg. Zentrums der Ruprecht-Karls-Univ., Im Neuenheimer Feld 110, D-6900 Heidelberg, FRG) 38, 723 (1989)

Sonographischer Nachweis einer Epiphysiolysis capitis humeri. Hofweber, K., Herterich, R. (Kinderkrankenhaus St. Marien, Grillparzerstr.9, D-8300 Landshut, FRG) 38, 727 (1989)

Pediatric Surgery International (Berlin)

Vesicoureteral reflux in boys. Gonzales, Jr., E.T. et al. (Children's Hosp., 6621 Fannin, Suite R402, Houston, TX 77030, USA) 4, 154 (1989)

Ureteroceles in infancy and childhood: in search of the correct surgical approach. Frey, P., Cohen, S.J. (Dept. of Ped. Surg., Univ. Children's Hosp., Roemergasse 8, CH-4005 Basel, Switzerland) 4, 175 (1989)

Neurofibrosarcoma - a complication of von Recklinghausen's disease. Wijesinha, S. S. et al. (Cole, W. G., Dept. of Orthop. Surg., The Royal Children's Hosp., Flemington Rd., Mélbourne 3052, Australia) 4, 193 (1989)

Renal artery thrombosis - an unusual complication following removal of a neuroblastoma. Yamagiwa, I. et al. (Second Dept. of Surg., Univ., School of Med., Iida-nishi 2-2-2, Yamagata, Japan 990-23) 4, 208 (1989)

The anterior sacral meningocele - a rare cause of constipation in childhood. Siplovich, L. et al. (Dept. of Ped. Surg., Centrla Emek Hosp., Afula 18101, Israel) 4, 214 (1989)

Rhabdomyosarcoma of the common bile duct imitating choledochal cyst. Bar-Maor, J.A. et al. (Dept. of Paed. Surg., Rambam Med. Center, Haifa 35254, Israel) 4, 277 (1989)

Neonatal bowel obstruction due to meconium adhesions. De Miscault, G. et al. (Clinique de Chirurgie Péd., Hôpital d'Enfants, Allée du Morvan, F-54511 Vandœuvre, Cedex, France) 4, 283 (1989)
Paraduodenal hernia in childhood. Gomez-Fraile, A. et al. (c/Viriato, 20, E-28010, Madrid, Spain) 4, 286 (1989)

Radiologie. Journal du CEPUR (Berlin)

Les calcifications discales de l'enfant. Dupuis, MG, Dosch, JC (Serv. de Rad., Centre de Traumatologie et d'Orthop., 10, av. A. Baumann, F-67400 Illkirch Graffenstaden, France) 9, 117 (1989)

Röntgen-Blätter (Stuttgart)

X-ray findings in Askin tumours. Crone-Münzebrock, W. et al. (Abt. Röntgendiagn., Univ.-Krankenhaus, Martinistr. 52, D-2000 Hamburg 20, FRG) 42, 271 (1989)

\section{Skeletal Radiology (Berlin)}

Radiographic appearance of healed extremity fractures in children with spinal cord lesions. Hyre, H. M., Stelling, C. B. (Univ., Albert B. Chandler Med. Center, Dept. of Diagn. Rad, 800 Rose St., Lexington, KY 40536-0084, USA) 18, 189 (1989)

Ultrasonic diagnosis of Osgood-Schlatter and Sinding-Larsen-Johansson diseases of the knee. De Flaviis, L. et al. (v. le Tunisia 22, I-20124 Milano, Italy) 18, 193 (1989)

Radiographic observations of subtalar joint effusion in two children. Eggli, K. D. (The Milton S. Hershey Med. Center, Univ, P.O. Box 850, Hershey, PA 17033, USA) 18, 207 (1989)

Chondroblastoma: case report 537. Pignatti, G., Nigrisoli, M. (Nigrisoli, M., Bone Tumor Center, 1st Orthop. Clinic, Ist. Ortop. Rizzoli, Via Codivilla 9, I-40.136 Bologna, Italy) 18, 225 (1989)

Osteofibrous dysplasia of tibia: case report 543. Abdelwahab, I.F. et al. (Dept. of Rad., Box 1234, Mount Sinai Med. Center, One Gustave L. Levy Place, New York, NY 10029-6574, USA) 18, 249 (1989)

Ultraschall in der Medizin (Stuttgart)

Transcranial Doppler sonography in childhood Part I: Examination technique and biological influences. Bode, $\mathbf{H}$. (Univ.-Kinderspital, Römergasse 8, CH-4005 Basel, Switzerland) 10, 54 (1989) 